University of Nebraska - Lincoln

DigitalCommons@University of Nebraska - Lincoln

David Hage Publications

Published Research - Department of Chemistry

$11-15-2010$

\title{
Chromatographic Studies of Changes in Binding Of Sulfonylurea Drugs to Human Serum Albumin Due To Glycation and Fatty Acids
}

Sara B. G. Basiaga

University of Nebraska - Lincoln

David S. Hage

University of Nebraska - Lincoln, dhage1@unl.edu

Follow this and additional works at: http:// digitalcommons.unl.edu/chemistryhage

Basiaga, Sara B. G. and Hage, David S., "Chromatographic Studies of Changes in Binding Of Sulfonylurea Drugs to Human Serum Albumin Due To Glycation and Fatty Acids" (2010). David Hage Publications. 44.

http://digitalcommons.unl.edu/chemistryhage/44

This Article is brought to you for free and open access by the Published Research - Department of Chemistry at DigitalCommons@University of Nebraska - Lincoln. It has been accepted for inclusion in David Hage Publications by an authorized administrator of DigitalCommons@University of Nebraska - Lincoln. 
Published in final edited form as:

J Chromatogr B Analyt Technol Biomed Life Sci. 2010 November 15; 878(30): 3193-3197. doi:10.1016/ j.jchromb.2010.09.033.

\title{
CHROMATOGRAPHIC STUDIES OF CHANGES IN BINDING OF SULFONYLUREA DRUGS TO HUMAN SERUM ALBUMIN DUE TO GLYCATION AND FATTY ACIDS
}

\author{
Sara B. G. Basiaga and David S. Hage* \\ Chemistry Department, University of Nebraska, Lincoln, Lincoln, NE 68588-0304 (USA)
}

\section{Abstract}

This report examines the use of high-performance affinity chromatography as a screening tool for studying the change in binding by sulfonylurea drugs to the protein human serum albumin (HSA) during diabetes. The effects of both the non-enzymatic glycation of HSA and the presence of fatty acids on these interactions were considered using a zonal elution format. It was found that there was significant increase (i.e., 2.7 to 3.6-fold) in the relative retention of several sulfonylurea drugs (i.e., acetohexamide, tolbutamide, glybenclamide and gliclazide) on columns containing normal versus glycated HSA. The addition of various long chain fatty acids to the mobile phase gave the same trend in retention for the tested drugs on both the HSA and glycated HSA columns, generally leading to lower binding. Most of the fatty acids examined produced similar or moderately different relative shifts in retention; however, palmitic acid was found to produce a much larger change in retention on columns containing glycated HSA versus normal HSA under the conditions used in this study.

\section{Keywords}

Human serum albumin; High-performance affinity chromatography; Glycation; Drug-protein binding; Sulfonylurea drugs; Fatty acids

\section{Introduction}

\begin{abstract}
Human serum albumin (HSA) is an important carrier protein in serum for many drugs, small hormones and fatty acids [1,2]. In the presence of glucose, HSA can undergo the nonenzymatic addition of this sugar to lysine residues or the N-terminus in a process known as glycation. This process initially forms a reversible Schiff base that can later rearrange to form a stable ketoamine, or Amadori product [3-5]. Healthy individuals have between $6-15 \%$ of HSA present as glycated HSA (G-HSA) in serum, while persons with type II diabetes (i.e., a condition in which there is an elevated level of glucose in blood) often have $15-30 \%$ glycated HSA in serum $[5,6]$. Previous studies have indicated that glycation-related modifications can occur near the two main drug binding sites on HSA [3,4,7-9]. It has been proposed that presence of such modifications can influence the binding of drugs and other substances to this protein [7-9].
\end{abstract}

\footnotetext{
(C) 2010 Elsevier B.V. All rights reserved.

*Author for correspondence: Phone, (402) 472-2744; Fax, (402) 472-9402; dhage@unlserve.unl.edu.
}

Publisher's Disclaimer: This is a PDF file of an unedited manuscript that has been accepted for publication. As a service to our customers we are providing this early version of the manuscript. The manuscript will undergo copyediting, typesetting, and review of the resulting proof before it is published in its final citable form. Please note that during the production process errors may be discovered which could affect the content, and all legal disclaimers that apply to the journal pertain. 
Sulfonylureas are drugs commonly used to treat type II diabetes and include acetohexamide, tolbutamide, glybenclamide (i.e., glyburide) and gliclazide [10-12]. These drugs are highly bound to serum proteins, and in particular to HSA [13,14]. It has been shown for some sulfonylureas (e.g., acetohexamide and tolbutamide) that these interactions occur at both of the major binding sites of HSA (i.e., Sudlow sites I and II) [15-17]. High-performance affinity chromatography (HPAC) is a tool that has recently been used in detailed studies to characterize the binding of acetohexamide and tolbutamide with HSA to examine the effects of glycation on the site-specific interactions of these drugs and other agents at Sudlow sites I and II [15-18]. Along with glycation, the effect on these interactions due to the binding of HSA to fatty acids (which may also be elevated during diabetes) is also of interest because of the possible combined effect these factors can have on drug-protein interactions during diabetes [6]. This work will explore the use of HPAC columns containing HSA or G-HSA in a screening assay to compare of the effects of glycation and the presence of various fatty acids found in serum on the binding of common sulfonylurea drugs to HSA. This work should provide some initial clues as to the relative effects of glycation and binding by fatty acids on these interactions.

\section{Experimental}

\subsection{Reagents}

The HSA (essentially fatty-acid free, lot no. 104K7636), G-HSA (essentially fatty-acid free, lot 115K6108), lauric acid, linoleic acid, myristic acid, oleic acid, palmitic acid, stearic acid, acetohexamide, gliclazide, glybenclamide and tolbutamide were obtained from SigmaAldrich (St. Louis, MO, USA). The G-HSA was prepared commercially using in vitro methods under proprietary conditions by incubating a fixed concentration of D-glucose with HSA at $37{ }^{\circ} \mathrm{C}$ for periods of time that were no longer than a week. The preparation of GHSA that was used in this study contained the equivalent of $3.6 \mathrm{~mol}$ hexose $/ \mathrm{mol} \mathrm{HSA}$, as reported by the manufacturer. Mass spectrometric studies on the location and types of modifications that occur in this type of preparation have been reported in Refs. [7,8], including information on modifications that have been noted at or near Sudlow sites I and II of glycated HSA. The Nucleosil 300-7 silica (7 $\mu$ m particle diameter, $300 \AA$ pore size) was from Macherey Nagel (Düren, Germany). Reagents for the bicinchoninic acid (BCA) protein assay were from Pierce (Rockford, IL, USA). All solutions were prepared using water from a Barnstead Nanopure water system (Dubuque, IA, USA).

\subsection{Apparatus}

The chromatographic system consisted of a Hitachi L-6000 pump (Pleasanton, CA, USA), a ThermoSeparations SpectraSystem AS3000 autosampler (Waltham, MA, USA) equipped with a $10 \mu \mathrm{L}$ sample loop, and a Waters $481 \mathrm{UV}$ detector (Milford, MA, USA). The detection wavelengths were as follows: $248 \mathrm{~nm}$, acetohexamide; $226 \mathrm{~nm}$, gliclazide and tolbutamide; and $228 \mathrm{~nm}$, glybenclamide. The columns were held at $37( \pm 0.1)^{\circ} \mathrm{C}$ by using a water jacket (Fisher Scientific, Pittsburgh, PA, USA) and recirculating water bath (CH/P Bath and Circulator Model 2067, Forma Scientific Inc., Marietta, OH, USA). Data were acquired using in-house programs written in LabView 8.0 (National Instruments, Austin, TX, USA) and processed using PeakFit 4.12 (SeaSolve Software, San Jose, CA, USA).

\subsection{Methods}

Nucleosil 300-7 silica was converted into diol silica [19] and portions of this diol silica were used to immobilize HSA or G-HSA by the Schiff base method [20]. The immobilization of HSA by this Schiff base method has been shown to mainly occur at the $N$-terminus or at a few lysines that are not located at Sudlow sites I or II and that tend to be different from the residues that are involved in glycation $[7,8,21]$. The Schiff base method is a relatively 
simple immobilization technique that has already been demonstrated to give binding data for sulfonylurea drugs that are in good agreement with solution phase results for both glycated HSA and normal HSA [13,15-17]; however, other immobilization methods based on the coupling of HSA through its free cysteine [22] or through entrapment [23] could also be utilized for such work. Part of the diol silica was taken through the Schiff base method with no protein being added to create a control support. All of the final supports were stored in $\mathrm{pH} 7.4,67 \mathrm{mM}$ potassium phosphate buffer at $4^{\circ} \mathrm{C}$ until use. The protein content of the HSA and G-HSA supports was determined in triplicate by using a BCA assay, with soluble HSA or G-HSA being used as the standard and the control support being used as the blank. The HSA support was found to contain $25( \pm 2.5) \mathrm{mg}$ HSA per g silica, and the G-HSA support contained $15.4( \pm 0.7) \mathrm{mg}$ G-HSA per $\mathrm{g}$ silica.

Each column used in this study was $2.0 \mathrm{~cm} \times 2.1 \mathrm{~mm}$ I.D. and was downward slurry packed with the desired support at $3500 \mathrm{psi}(24.1 \mathrm{MPa})$ for $2 \mathrm{~h}$ with $\mathrm{pH} 7.4,67 \mathrm{mM}$ potassium phosphate buffer being utilized as the packing solution. These columns were stored at $4{ }^{\circ} \mathrm{C}$ in $\mathrm{pH} 7.4,67 \mathrm{mM}$ phosphate buffer and were used over the period a few months (approximate total run time, $100 \mathrm{~h}$ at $1 \mathrm{ml} / \mathrm{min}$ ). It has been found in related studies that such columns are stable for at least six months under these operating conditions [20].

Stock sample solutions were prepared by dissolving $100 \mu \mathrm{M}$ acetohexamide, gliclazide, glybenclamide or tolbutamide in $\mathrm{pH} 7.4,67 \mathrm{mM}$ potassium phosphate buffer. In the case of glybenclamide, $850 \mu \mathrm{M} \beta$-cyclodextrin was also added to the solution to act as a solubilizing agent, as has been used in previous work with other low solubility drugs on HSA columns [24]. The stock solutions were diluted using $\mathrm{pH} 7.4,67 \mathrm{mM}$ potassium phosphate buffer to give $5 \mu \mathrm{M}$ working samples of acetohexamide, gliclazide or tolbutamide and a $25 \mu \mathrm{M}$ working solution of glybenclamide (note: a higher concentration of glybenclamide was required because of its high retention and broad peaks on the HSA and G-HSA columns, which made it difficult to detect lower concentration samples). Although these sample concentrations were higher than the typical levels of these drugs in serum at therapeutic doses [25], it is important to note in this work that only a small pulse of each drug was injected to probe the overall binding of the drug with normal HSA or glycated HSA. It was also found that no significant changes in retention occurred when using slightly higher sample concentrations of these drugs, indicating that linear elution conditions were present under the conditions used in this study (i.e., conditions in which the results would reflect those that would be obtained in solution at low concentrations of each drug versus HSA) [26]. It was determined in control experiments that the presence of $\beta$-cyclodextrin in the glybenclamide samples did not have any significant effect on the interactions between HSA and this drug, as has been noted with other solutes [24].

All samples were injected in triplicate at $37^{\circ} \mathrm{C}$ and at $0.5 \mathrm{~mL} / \mathrm{min}$ in the presence of $\mathrm{pH} 7.4$, $67 \mathrm{mM}$ potassium phosphate buffer or the same buffer containing a known concentration of a fatty acid (see Table 2 for a list of the fatty acids and concentrations used in this study). Similar injections of a $5 \mu \mathrm{M}$ solution of sodium nitrate (i.e., a non-retained solute) in $\mathrm{pH} 7.4$, $67 \mathrm{mM}$ phosphate buffer were made to measure the void time of each column. No significant changes in retention were noted when using slower flow rates for injection, as has been noted in similar work with other drugs on HSA columns [26]. Injections on the control column indicated that all of the tested drugs had no significant non-specific retention on this support (i.e., binding that made up less than $3 \%$ of the total retention on the HSA or G-HSA columns). 


\section{Results and Discussion}

Affinity chromatography has been shown in the past to be a useful tool in characterizing and screening the overall affinity of various drugs with normal HSA. For instance, the retention factor $(k)$ measured for an injected drug on an affinity column can be directly related to the global affinity of the drug for an immobilized protein such as HSA [26], as shown in Eqn. (1).

$$
k=\frac{\left(K_{A 1} n_{1}+\cdots K_{A n} n_{n}\right) m_{L}}{V_{M}}
$$

In this equation, $K_{A I}$ through $K_{A n}$ are the association equilibrium constants for binding sites 1 through $n, n_{l}$ through $n_{n}$ represent the number of each type of site in the column, $m_{L}$ is the moles of binding sites in the column, and $V_{M}$ is the column void volume. In this case, the global association equilibrium constant is the summation of the $K_{A} n$ terms, as could be used to examine a drug with multiple sites of interaction with HSA (e.g., Sudlow sites I and II).

Figure 2 shows some typical chromatograms obtained when a small amount of a sulfonylurea drug was injected onto affinity columns containing normal or glycated HSA. Table 1 summarizes the retention factors measured for each of the tested drugs. It was found that glycated HSA consistently gave higher retention, and thus stronger binding, than normal HSA. After these results were normalized for the different protein contents of the columns, the glycated HSA column gave a 2.7 to 3.6-fold higher retention than normal HSA for the injected drugs. The relative change in retention was approximately the same for all of the tested sulfonylureas regardless of the different structures of their side chains. These results agreed with control experiments based on ultrafiltration using similar preparations of normal HSA and glycated HSA plus low-to-therapeutic levels of the drugs and physiological concentrations of each protein [13]. According to Eqn. (1), this result would correspond to a proportional difference in the global affinities of these two protein preparations for the drugs.

The trends noted in Table 1 agree with recent observations that have been made in detailed frontal analysis studies and competition studies examining the interactions of acetohexamide and tolbutamide with normal HSA versus glycated HSA [16,17]. In a separate study, no statistically significant change in the overall percent binding of glybenclamide was seen in going from normal HSA to glycated HSA [27]. The different conclusions reached in this current study and in Ref. [27] may reflect changes in binding affinity with the level of glycation of HSA [16,17]. However, Ref. [27] also involved the measurement of percent binding and attempted to compare changes in this value for drug samples with $98 \%$ or greater binding to HSA; under these conditions, an increase in binding affinity with glycation would have been difficult to observe with the experimental method that was employed. This was not an issue with the HPAC method used in this current report because an increase in affinity would lead to a proportional increase in retention for even a drug with a high affinity for a protein.

Another way in which zonal elution can be employed is to study the effect of one solute on the binding of another to HSA [26]. This report compared the effect of several long chain fatty acids on the overall binding of sulfonylurea drugs to normal HSA versus glycated HSA. Table 2 lists the fatty acids and concentrations that were examined (note: concentrations up to 100-fold below normal serum concentrations were selected in this case to simplify the analysis and emphasize the higher affinity interactions that might occur between these additives and injected drugs). Typical chromatograms that were obtained in 
the absence and presence of these fatty acids are shown in Figure 2. The addition of most of the fatty acids produced a decrease in the observed retention for the sulfonylurea drugs on either normal HSA or glycated HSA. It is known that fatty acids can lead to a variety of effects in the binding of drugs to normal HSA, including direct competition and multisite interactions that can include allosteric effects [28].

It was found under these conditions for most of the tested drugs that there was a gradual change in the observed retention as the fatty acid concentration was increased (see example in Figure 3). Table 2 summarizes the overall change in retention that was noted on both the normal HSA and glycated HSA columns for each of the tested drugs. Similar trends were noted in control experiments using ultrafiltration and the same drugs and fatty acids [13]. In all cases except one, a decrease in retention for the sulfonylurea drugs was seen as the concentration of fatty acids in the mobile phase was increased (note: the single exception was for glybenclamide in the presence of myristic acid, and even in this case there was only a slight increase in retention). Acetohexamide, gliclazide and tolbutamide gave overall changes in retention that were similar between the normal and glycated HSA columns. When compared to these other drugs, glybenclamide gave similar or lower changes in retention except for a small increase seen in the presence of linoleic acid and normal HSA; this latter difference may have been due to the larger structure and lower solubility of glybenclamide or secondary effects due to the use of a small amount of $\beta$-cyclodextrin in the glybenclamide samples as a solubilizing agent.

Fatty acids which lead to only relatively small changes in the retention for sulfonylurea drugs on the normal and glycated HSA columns (i.e., values in Table 2 that varied by less than $10 \%$ ) included myristic acid and oleic acid in work with acetohexamide, glyclazide and tolbutamide; and lauric acid, linoleic acid, and oleic acid with glybenclamide. Fatty acids which created moderate differences in retention shifts on the two types of HSA columns (i.e., values in Table 2 that differed by 11-25\%) included lauric acid, linoleic acid and stearic acid in experiments conducted with acetohexamide; lauric acid, linoleic acid, and stearic acid in work with gliclazide; lauric acid, linoleic acid, and stearic acid for tolbutamide; and myristic acid and stearic acid for glybenclamide. Palmitic acid demonstrated a much larger variation in retention shifts that was seen for any of the other tested fatty acids. In this latter case, the values in Table 2 for the normal HSA and glycated HSA columns differed by $41-73 \%$ for all of the tested drugs under the conditions used in this study.

\section{Conclusions}

This report used high-performance affinity columns containing normal HSA or glycated HSA to examine the changes in overall affinity and binding that occur for various sulfonylurea drugs with such proteins. It was found for all of the tested drugs that the glycated HSA had higher overall binding under linear elution conditions for the protein preparations that were used in this study. This binding also tended to decrease in the presence of several common fatty acids that are found in serum. In many cases the effects of these fatty acids on the binding of sulfonylurea drugs were similar or only moderately different for normal HSA versus glycated HSA. However, for palmitic acid there was a much larger change in this binding to glycated HSA compared to normal HSA.

This work demonstrates how HPAC columns can be used as screening tools to examine and compare multiple effects on the binding of drugs to proteins such as HSA. The trends observed in this study indicate that both protein glycation and the presence of fatty acids in serum, as occurs during diabetes, can alter the overall binding of sulfonylurea drugs to HSA. More detailed studies are now in progress to examine these effects over a broader range of conditions and levels of protein glycation, as well as to determine the mechanisms by which 
fatty acids may affect the interactions of sulfonlyurea drugs with normal HSA or glycated HSA. The expected result of this work is a better description of how the serum protein interactions of sulfonylurea drugs may be altered during diabetes, which should allow for a more effective use of such agents in treating this disease.

\section{Acknowledgments}

This research was supported by the National Institutes of Health under grant R01 DK069629 and was conducted in facilities that were renovated under NIH grant RR015468.

\section{References}

[1]. Peters, T, Jr.. All About Albumin. Academic Press; San Diego, CA: 1996.

[2]. Kragh-Hansen U, Watanabe H, Nakajou K, Iwao Y, Otagiri M. J. Mol. Biol. 2006; 363:702. [PubMed: 16979183]

[3]. Guthrow CE, Morris MA, Day JF, Thorpe SR. Proc. Natl. Acad. Sci. U.S.A. 1979; 76:4258-4261. [PubMed: 291961]

[4]. Kahn MW, Rasheed Z, Kahn WA, Ali R. Biochemistry. 2007; 72:146-152. [PubMed: 17367291]

[5]. Sattarahmady N, Moosavi-Movahedi AA, Ahmad F, Hakimelahi GH, Habibi-Rezaei M, Saboury AA, Sheibani N. Biochem. Biophys. Acta. 2007; 1770:933-942. [PubMed: 17368729]

[6]. Gwilt PR, Nahhas RR, Tracewell WG. Clin. Pharmacokin. 1991; 20:477.

[7]. Wa C, Cerny RL, Clarke WA, Hage DS. Clin. Chim. Acta. 2007; 385:48. [PubMed: 17707360]

[8]. Barnaby OS, Wa C, Cerny RL, Clarke W, Hage DS. Clin. Chim. Acta. 2010; 411:1102. [PubMed: 20394739]

[9]. Coussons PJ, Jacoby J, Price NC, Kelly SM, Hunt JV. Free Radicals Biol. Med. 1997; 22:12171227.

[10]. Lebovitz H. Med. Clin. North Am. 2004; 88:847-863. [PubMed: 15308382]

[11]. Mizuno CS, Chittiboyina AG, Kurtz TW, Pershadsingh HA, Avery MA. Curr. Med. Chem. 2008; 15:61-74. [PubMed: 18220763]

[12]. Krentz AJ, Patel MB, Baily CJ. Drugs. 2008; 68:2131-2162. [PubMed: 18840004]

[13]. Anguizola, J. M.S. Thesis. University of Nebraska; Lincoln, NE: 2009.

[14]. Koyama H, Sugioka N, Uno A, Mori S, Nakajima K. Biopharmaceut. Drug Dispos. 1997; 18:791.

[15]. Joseph KS, Hage DS. J. Chromatogr. B. 2010; 878:1590.

[16]. Joseph KS, Anguizola J, Hage DS. J. Chromatogr. B. in press. (DOI: 10.1016/j.jchromb. 2010.08.021).

[17]. Joseph KS, Anguizola J, Hage DS. J. Pharm. Biomed. Anal. in press. (DOI: 10.1016/j.jbpa. 2010.09.003).

[18]. Joseph KS, Hage DS. J. Pharm. Biomed. Anal. 2010; 53:811. [PubMed: 20537832]

[19]. Ruhn PF, Garver S, Hage DS. J. Chromatogr. A. 1996; 669:9-19. [PubMed: 8055106]

[20]. Loun B, Hage DS. J. Chromatogr. 1992; 579:225-235. [PubMed: 1429970]

[21]. Wa C, Cerny RL, Hage DS. Anal. Chem. 2006; 78:7967. [PubMed: 17134129]

[22]. Mallik R, Wa C, Hage DS. Anal. Chem. 2007; 79:1411. [PubMed: 17297940]

[23]. Jackson AJ, Xuan H, Hage DS. Anal. Biochem. 2010; 404:106. [PubMed: 20470745]

[24]. Chen J, Ohnmacht CM, Hage DS. J. Chromatogr. A. 2004; 1033:115-126. [PubMed: 15072296]

[25]. Groop L, Wahlin-Boll E, Groop P-H, Totterman K-J, Melander A, Tolppanen E-M, Fyhrqvist F. Eur. J. Clin. Pharm. 1985; 28:697.

[26]. Hage DS, Jackson A, Sobansky MR, Schiel JE, Yoo MJ, Joseph KS. J. Sep. Sci. 2009; 32:835. [PubMed: 19278006]

[27]. Olsen KM, Kearns GL, Kemp SF. J. Clin. Pharmacol. 1995; 35:739. [PubMed: 7560255]

[28]. Noctor TAG, Wainer IW, Hage DS. J. Chromatogr. 1992; 577:305. [PubMed: 1400761] 


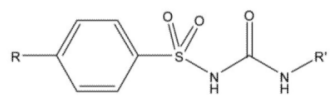

Basic structure

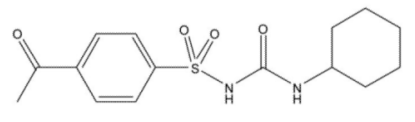

Acetohexamide

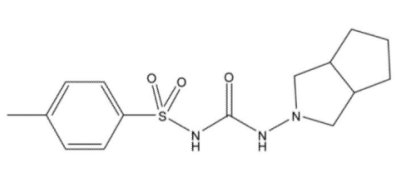

Gliclazide

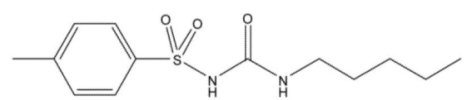

Tolbutamide

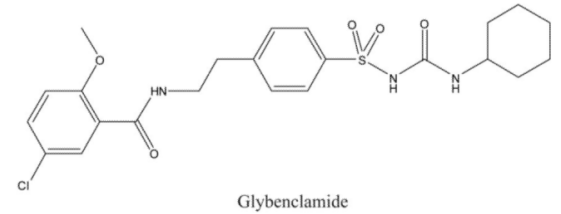

Figure 1.

Structures of sulfonylurea drugs examined in this study. 


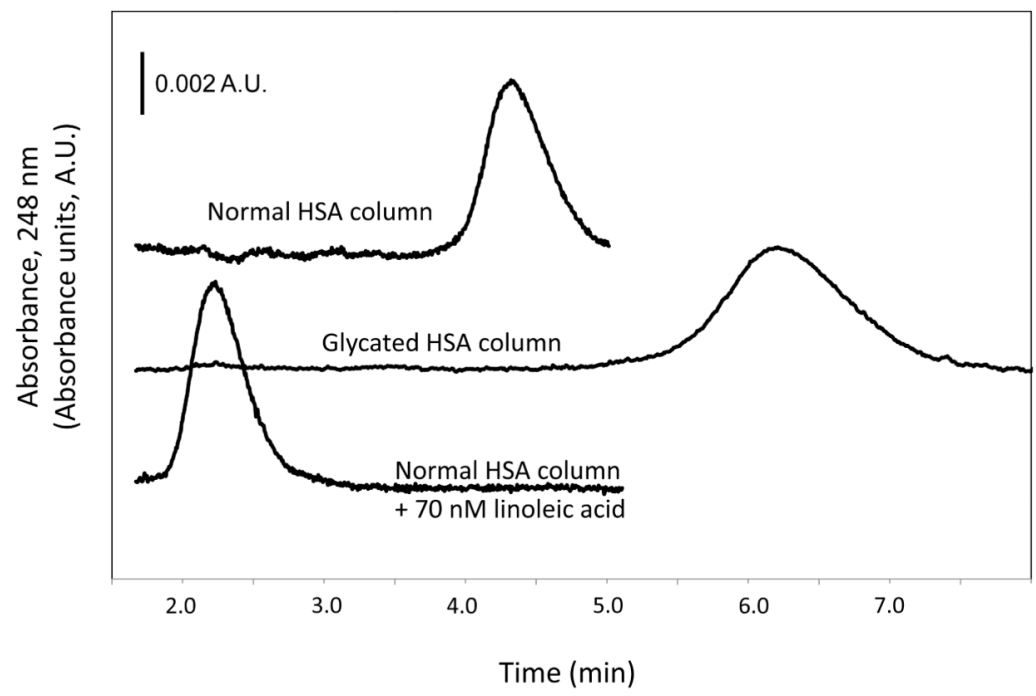

Figure 2.

Chromatograms for acetohexamide on columns containing normal HSA or glycated HSA in presence of only $\mathrm{pH} 7.4,67 \mathrm{mM}$ potassium phosphate buffer or normal HSA in the presence of the same buffer containing $70 \mathrm{nM}$ linoleic acid. 


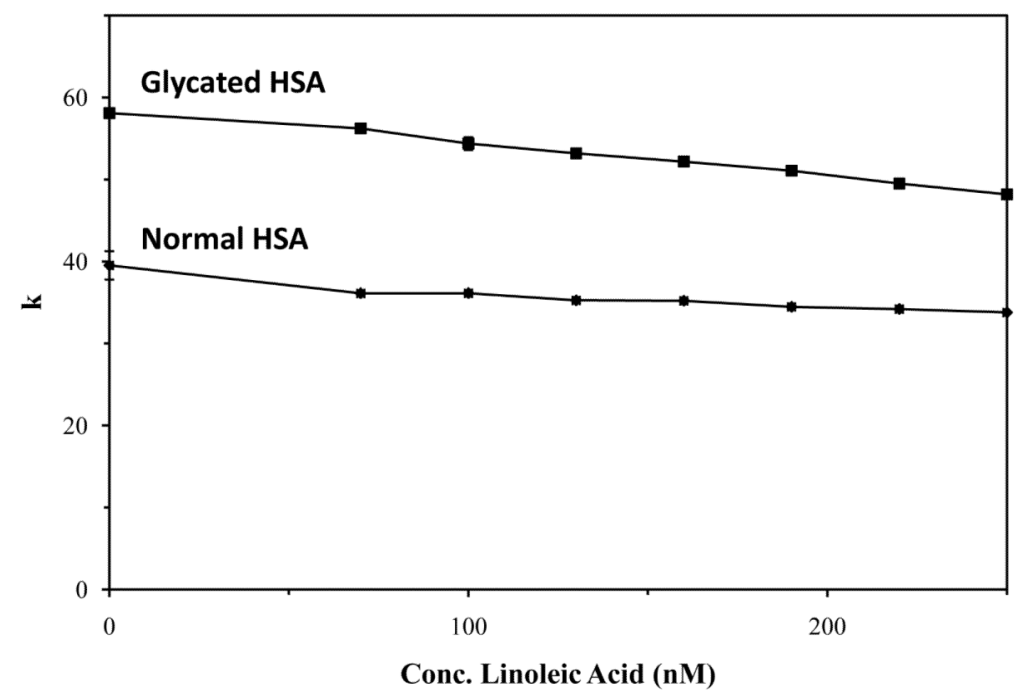

Figure 3.

Change in retention factor for glyblenclamide on columns containing (a) normal HSA or (b) glycated HSA in the presence of increasing concentrations of linoleic acid. The errors bars, which are similar in size to the data markers in most cases, represent a range of \pm 1 S.D. 
Table 1

Retention of various sulfonylurea drugs on columns containing normal or glycated HSA

\begin{tabular}{llc}
\hline Drug/protein & Retention factor, $\boldsymbol{k}$ & $\begin{array}{c}\text { Normalized retention factor, } \\
\boldsymbol{k} /(\text { protein content) }\end{array}$ \\
Normal HSA & & $0.19( \pm 0.02)$ \\
Acetohexamide & $4.7( \pm 0.4)$ & $0.042( \pm 0.005)$ \\
Glybenclamide & $1.05( \pm 0.07)$ & $0.099( \pm 0.011)$ \\
Gliclazide & $2.5( \pm 0.1)$ & $1.49( \pm 0.15)$ \\
Tolbutamide & $37( \pm 2)$ & $0.56( \pm 0.03)$ \\
Glycated HSA & & $0.15( \pm 0.01)$ \\
Acetohexamide & $8.6( \pm 0.2)$ & $0.28( \pm 0.02)$ \\
Glybenclamide & $2.3( \pm 0.1)$ & $4.0( \pm 0.3)$ \\
Gliclazide & $4.4( \pm 0.1)$ & \\
Tolbutamide & $61( \pm 4)$ & \\
\hline
\end{tabular}

${ }^{a}$ All of these studies were conducted at $37^{\circ} \mathrm{C}$ in the presence of $\mathrm{pH} 7.4,67 \mathrm{mM}$ potassium phosphate buffer. The values in parentheses represent a range of \pm 1 S.D.

$b$ These normalized retention factors were calculated by dividing the listed retention factors by a measured protein content for the given supports of $25( \pm 2.5) \mathrm{mg}$ HSA per g silica or $15.4( \pm 0.7) \mathrm{mg}$ G-HSA per $\mathrm{g}$ silica. 
Table 2

Relative change in retention factor for sulfonylurea drugs on a normal and glycated HSA columns in the presence of various fatty acids

\begin{tabular}{lcccc}
\hline \multicolumn{1}{c}{$\begin{array}{c}\text { Fatty acid } \\
\text { Concentration range) }\end{array}$} & \multicolumn{3}{c}{ Drug and relative change in retention } \\
Normal HSA & Acetohexamide & Gliclazide & Tolbutamide & Glybenclamide $b$ \\
Lauric acid (0-60 nM) & $27 \%$ & $41 \%$ & $26 \%$ & $8 \%$ \\
Linoleic acid (0-250 nM) & $3 \%$ & $4 \%$ & $4 \%$ & $15 \%$ \\
Myristic acid (0-30 nM) & $27 \%$ & $33 \%$ & $22 \%$ & $(7 \%)$ \\
Oleic acid (0-546 nM) & $15 \%$ & $8 \%$ & $16 \%$ & $11 \%$ \\
Palmitic acid (0-400 nM) & $10 \%$ & $15 \%$ & $11 \%$ & $11 \%$ \\
Stearic acid (0-80 nM) & $5 \%$ & $4 \%$ & $4 \%$ & $2 \%$ \\
Glycated $H S A$ & & & & \\
Lauric acid (0-6 nM) & $14 \%$ & $18 \%$ & $13 \%$ & $15 \%$ \\
Linoleic acid (0-250 nM) & $18 \%$ & $22 \%$ & $18 \%$ & $17 \%$ \\
Myristic acid (0-30 nM) & $25 \%$ & $31 \%$ & $23 \%$ & $15 \%$ \\
Oleic acid (0-546 nM) & $9 \%$ & $15 \%$ & $11 \%$ & $12 \%$ \\
Palmitic acid (0-400 nM) & $81 \%$ & $79 \%$ & $84 \%$ & $52 \%$ \\
Stearic acid (0-80 nM) & $20 \%$ & $26 \%$ & $20 \%$ & $18 \%$ \\
\hline
\end{tabular}

${ }^{a}$ All of these studies were conducted at $37^{\circ} \mathrm{C}$ in the presence of $\mathrm{pH} 7.4,67 \mathrm{mM}$ potassium phosphate buffer.

${ }^{b}$ All of the above relative changes represent a decrease in retention except for glybenclamide in the presence of myristic acid, which gave a slight increase in retention at the highest tested concentration of this fatty acid. 